\title{
Food and Macronutrient Intake of Elite Kenyan Distance Runners
}

\author{
V.O. Onywera, F.K. Kiplamai, P.J. Tuitoek, \\ M.K. Boit, and Y.P. Pitsiladis
}

\begin{abstract}
The food and macronutrient intake of elite Kenyan runners was compared to recommendations for endurance athletes. Estimated energy intake (EI: $2987 \pm 293 \mathrm{kcal}$; mean \pm standard deviation) was lower than energy expenditure (EE: $3605 \pm 119 \mathrm{kcal} ; P<0.001)$ and body mass (BM: $58.9 \pm 2.7 \mathrm{~kg}$ vs. $58.3 \pm 2.6 \mathrm{~kg} ; P<0.001)$ was reduced over the $7-\mathrm{d}$ intense training period. Diet was high in carbohydrate $(76.5 \%, 10.4 \mathrm{~g} / \mathrm{kg} \mathrm{BM}$ per day) and low in fat $(13.4 \%)$. Protein intake $(10.1 \% ; 1.3 \mathrm{~g} / \mathrm{kg} \mathrm{BM}$ per day) matched recommendations for protein intake. Fluid intake was modest and mainly in the form of water $(1113 \pm 269 \mathrm{~mL} ; 0.34 \pm 0.16 \mathrm{~mL} / \mathrm{kcal})$ and tea $(1243 \pm 348 \mathrm{~mL})$. Although the diet met most recommendations for endurance athletes for macronutrient intake, it remains to be determined if modifying energy balance and fluid intake will enhance the performance of elite Kenyan runners.
\end{abstract}

Key Words: Kenya, endurance athletes, diet, training, high altitude

The astonishing success of Kenyan runners in world athletics especially in the middle- and long-distance events has astounded scientists who have sought to explain the reason(s) for this phenomenon. Explanations have included genetic endowment $(11)$, favorable environmental conditions $(17,21)$ and unique dietary intake (13). There is much evidence in the literature regarding the advantages of optimal nutrition in endurance events. For example, carbohydrates (CHO) are important to maintain blood glucose levels during exercise and to replace muscle glycogen (2). Recommendations for endurance events range from 6 to $10 \mathrm{~g} \mathrm{CHO} / \mathrm{kg}$ body mass per day, depending on the athlete's total daily energy expenditure, gender, mode of exercise, and environmental conditions (2). Protein recommendations for endurance athletes range from 1.2 to $1.4 \mathrm{~g} / \mathrm{kg}$ body mass per day, and are typically achieved if energy intake is adequate to maintain body mass (2). Adequate fluid intake before, during, and after exercise is also necessary for optimal performance. Recommendations for fluid intake center on trying to balance fluid losses with suggestions such as athletes needing to drink at least 450 to $675 \mathrm{~mL}$ of fluid for every $0.5 \mathrm{~kg}$ of body mass lost during exercise (2). Such nutritional guidelines become

Onywera, Boit, and Pitsiladis are with the Dept of Exercise and Sports Science, Kenyatta University, P.O. Box 43844, Nairobi. Kenya. Kiplamai and Tuitoek are with the Dept of Foods, Nutrition and Dietetics, Egerton University, P.O. Box 536, Njoro, Kenya. Pitsiladis is also with the International Centre for East African Running Science, Institute of Biomedical and Life Sciences, University of Glasgow, Glasgow, G12 8QQ, UK 
more important during longer and harder exercise, and under more extreme environmental conditions - features that particularly characterize what little is known of the training experiences of Kenyan distance runners.

Two dietary intake studies of Kenyan runners have been carried out to date. The first, by Mukeshi and Thairu (14), evaluated the food intake of male Kenyan runners $2 \mathrm{~d}$ per month over a 3-month period using a combination of recall and direct observation. Incredibly, the average daily energy intake was reported to be $2340 \mathrm{kcal}$, less than the estimated average requirements (EARs: $2550 \mathrm{kcal}$ per day) for energy for the average male (8). Based on current thinking, such low energy intake would render it "impossible" to carry out and maintain optimal endurance training, hence the validity of this data can be questioned. The athletes in this study consumed on average $441 \mathrm{~g} \mathrm{CHO}(8.1 \mathrm{~g} / \mathrm{kg}$ body mass, approximately $75 \%$ of energy intake in the form of $\mathrm{CHO}$ ). The only other study of Kenyan runners assessed the food and macronutrient intake of male adolescent Kenyan runners using a 24-h recall and reported considerably higher average energy intakes (i.e., range from 2750 to $3558 \mathrm{kcal}$ per day) (6). These authors also reported a high $\mathrm{CHO}$ intake (daily CHO intake was $71 \pm 0.5 \%, 8.7 \pm 0.4 \mathrm{~g} / \mathrm{kg}$ body mass), and in line with current recommendations for optimal endurance performance.

A particular feature of Kenyan running that has received the most public and research attention is the disproportionately large number of Kenyan Olympians/ world champions who are of a distinct ethnic group called the Kalenjin who number about 3 million (i.e., $10 \%$ of the Kenyan population) and live in a relatively small geographical area of Kenya in the Great Rift Valley. Over a 10- y period from 1987 to 1997 , Kalenjin runners reportedly won a staggering $40 \%$ of all major international middle- and long-distance running competitions (13). Ideally, anyone interested in investigating a particular feature of this astonishing phenomenon would require a group of elite Kalenjin runners to be studied while living and training in their natural environment. Therefore, the purpose of the present study was to investigate the food and macronutrient intake of elite Kalenjin middle- and long-distance runners while training at a high altitude training camp situated in an area known for producing the majority of the Kenyan Olympians and world champions; the results obtained were compared to the intake recommended for endurance athletes (2). The daily energy expenditure of these runners was estimated, taking special care to record in detail all activities of daily living in addition to training.

\section{Methods}

\section{Subjects}

Ten elite Kenyan runners were invited to participate in this study and provided written informed consent prior to participation, which was approved by the local Kenyan authorities in Nairobi. Subjects were highly-trained competitive middle- and longdistance runners and included a number of world champions. All subjects belonged to a Kalenjin subtribe: 5 were Nandi, 3 were Keiyo, and there was 1 Tugen and 1 Sabaot. All subjects were based at a high-altitude training center (Global Sports Communication Training Camp, Kaptagat, Eldoret, Kenya) situated in the North Rift Valley (altitude: $2600 \mathrm{~m}$ above sea level, daytime ambient temperature: 15 to $25^{\circ} \mathrm{C}$ ), an area with a disproportionately large number of Kenyan Olympians/world champions. The physical characteristics of the runners are presented in Table 1. 


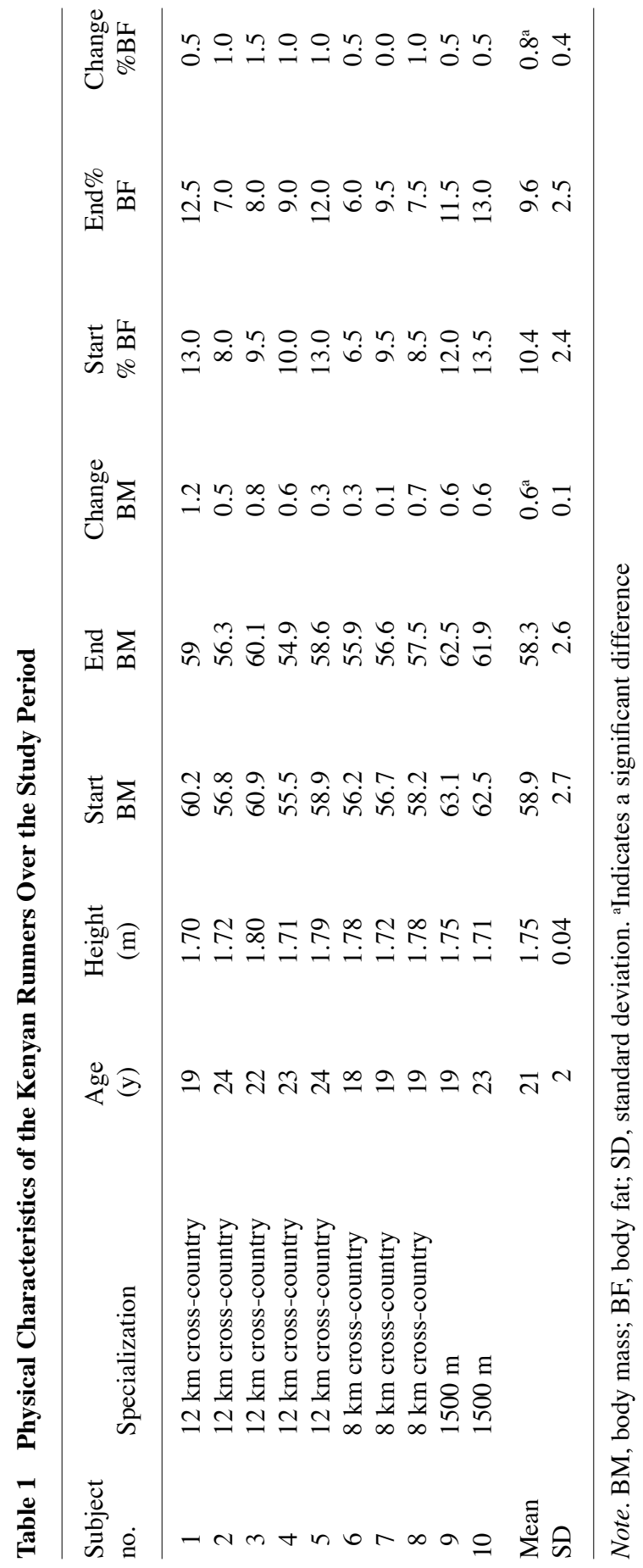




\section{Protocols}

The dietary intake of the subjects was measured daily for 7 consecutive days in the month of December during the summer season. Athletes were in peak condition and in readiness for the Kenyan national cross-country championships. During this 7-d period, subjects were requested to follow their normal diet and to weigh and record all food and drink consumed. Individual digital weighing scales accurate to $1 \mathrm{~g}$ were used. While at the training camp, meals and snacks were served at standard times each day: breakfast (08:00), mid-morning snack (10:00), lunch (13:00), afternoon snack (16:00), and dinner (19:00). All food items were weighed before and after cooking and the cooking method noted. Subjects were also required to continue weighing all food and drink when away from the camp. Athletes self-selected their portion sizes from the food provided ad libitum. The subjects consumed a limited variety of foods, mainly of vegetable sources. The staple foods were bread, boiled rice, boiled potatoes, porridge, cabbage, kidney beans and ugali (thick maize meal paste). Meat (mainly beef) was served at the training camp 4 times per week and consumed in modest amounts (approximately $100 \mathrm{~g}$ per day) although athletes were able to access more meat and other foods when visiting their rural homes. A significant amount of tea (with milk) was also consumed during the day.

The weighed dietary intake data were used to determine energy intake (EI) and diet composition using a computerized version of the National Food Composition Tables of Kenya (22). In addition, all available food labels describing the dietary composition of foods and drinks were collected and used to supplement the Food Composition Tables. The manager of the training camp assured investigators that the 7-d dietary intake measurement was representative of the athletes' dietary habits during a period of intense training. Athletes were encouraged to be as accurate as possible and all gave assurances to this effect at the end of the dietary assessment period. Typically, athletes did not receive any specific dietary recommendations from their coach/manager. No subjects used any kind of supplements including vitamins and minerals.

Total daily energy expenditure (EE) was assessed using physical activity ratios (PAR). In summary, energy expenditure is calculated from the duration of various work and leisure activities and assigning an energy cost to each (1). The energy cost is expressed as a multiple of basal metabolic rate (BMR). In the present study, BMR was calculated using the Schofield equations (20). Subjects were instructed to record in detail in a physical activity diary their time use and activity description each day (including the type, intensity, and duration of exercise training).

Nude body mass and percent body fat were measured each morning (05:30) during the assessment period using a leg-leg bioelectrical impedance meter (Tanita Body Fat Analyzer, TBF 521, Tanita Corp. of America, Inc., Arlington Heights, IL). Measurements were made after subjects had emptied their bladder and before the consumption of any food or drink. The estimates of percent body fat provided by the manufacturer's software were reported (the prediction equation used by the Tanita system is not disclosed by the manufacturer so the equation used cannot be presented). Although the leg-to-leg bioelectrical impedance system has been shown to reliably measure percent body fat in males when compared to underwater weighing (4), validation studies have not been carried out in this specific population. In addition, this method cannot distinguish between fat loss and fluid loss and data obtained can be compromised if subjects are in a state of dehydration (18). 
To overcome the problem of underreporting, one of the investigators spent 10 $\mathrm{d}$ living with the athletes at the training camp to familiarize and assist all subjects and cooking staff with data collection. It is thought that this personal interaction, conducted mainly in English but also in the local dialect, greatly improved the accuracy of all data collected. All participants reported finding the study experience enjoyable and worthwhile.

\section{Data Analysis}

Data were expressed as the mean \pm standard deviation. Energy balance (i.e., EI and EE over the $7 \mathrm{~d}$ ) was assessed statistically using a 2-way ANOVA for repeated measures, followed by Student's $t$-test for paired data for effects over time, as appropriate. Statistical analysis of the remaining data was carried out using 1 factor ANOVA for repeated measures, followed by Student's $t$-test for paired data, as appropriate. Statistical significance was declared when $P<0.05$.

\section{Results}

Athletes carried out most of their training collectively as 1 group 2 times a day, typically before breakfast and dinner. The morning run (06:00) comprised a 6 to 9 mile run carried out at either moderate or fast running pace (e.g., 11 to $15 \mathrm{mph}$ ) depending on athletic specialization and instructions received from the coach/ manager. Once per week the two $1500 \mathrm{~m}$ runners were transported to the nearby stadium (i.e., Kipchoge Keino Stadium, Eldoret) for high-intensity interval training. The afternoon runs (17:00) were 4 to 5 miles and usually run at an easier running pace (e.g., 6 to $9 \mathrm{mph}$ ). Subjects typically warmed-up for $10 \mathrm{~min}$ before each run and cooled-down for 20 min after each run. Warm-up and cool-down consisted of standard stretching exercises. Most of the other time at the training camp was spent resting, eating, or washing running clothes and shoes. Some athletes would also run during their spare time. The average energy expenditure of the subjects as estimated using PAR (see Table 2) was $3605 \pm 119 \mathrm{kcal}$.

Estimated energy intake over the 7-d assessment period (EI: $2987 \pm 293$ kcal) was significantly lower than estimated energy expenditure (EE: $3605 \pm 119$ kcal; $P<0.001$ ) (Figure 1). The calculated delta value (i.e. EI/EE) was $0.85 \pm 0.08$. Basal metabolic rate was estimated at $1577 \pm 39 \mathrm{kcal}$ per day. A small but statistically significant reduction in body mass (BM: $58.9 \pm 2.7 \mathrm{~kg}$ vs. $58.3 \pm 2.6 \mathrm{~kg} ; P<$ 0.001 ) and percent body fat [percent BF: $10.4 \pm 2.4 \%$ vs $9.6 \pm 2.5 \% ; P<0.001)$ ] was found over this period (Table 1). A significant reduction from baseline (i.e., day 1) in both body mass and percent body fat was detected from day 3 onwards (data not included).

Approximately $86 \%$ of the diet was from vegetable sources and only $14 \%$ was from animal sources (Table 3 ). The diet was very high in carbohydrate $(76.5 \%$, $10.4 \mathrm{~g} / \mathrm{kg}$ BM per day) and very low in fat (13.4\%) (Table 3). Daily carbohydrate intake was $607 \pm 57 \mathrm{~g}$ of which $95 \%$ came from vegetable sources (Table 3 ). Fat intake was $46 \pm 14 \mathrm{~g}$ of which $65 \%$ was derived from animal sources and $61 \%$ from pasteurized full-cream milk (Table 3$)$. Protein intake $(10.1 \% ; 1.3 \mathrm{~g} / \mathrm{kg} \mathrm{BM}$ per day), on the other hand, matched the $1.2 \mathrm{~g} / \mathrm{kg}$ BM per day recommendation for protein intake for endurance athletes (Figure 2). Protein intake was $75 \pm 12 \mathrm{~g}$ of which $67 \%$ came from vegetable foods (Table 3 ). Total fluid intake was modest 
Table 2 Estimated Daily Energy Expenditure According to Physical Activity Ratio

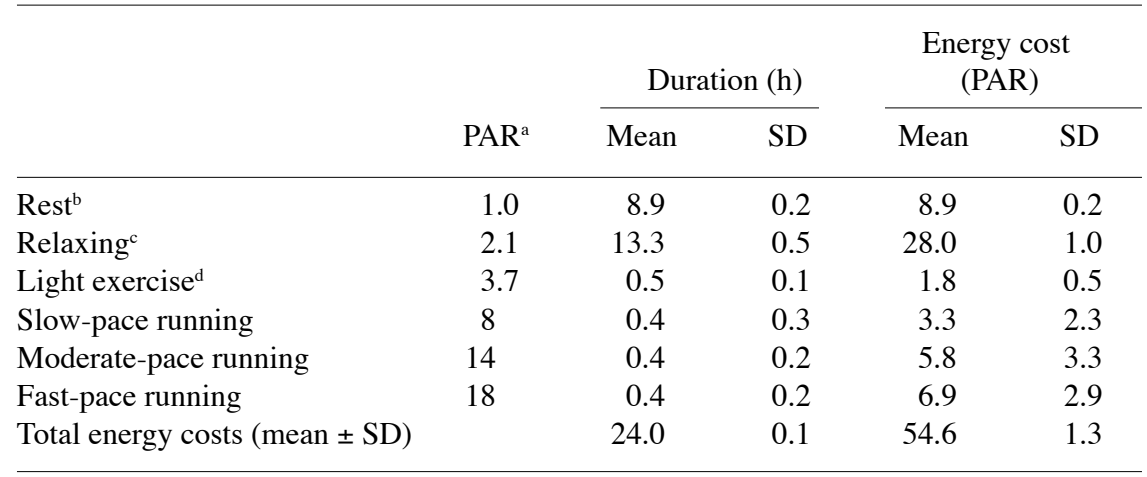

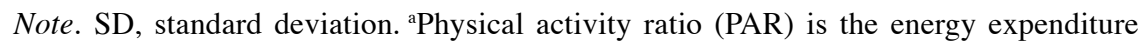

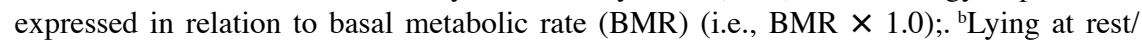
sleeping. 'Sitting down, standing, walking, talking. ${ }^{\mathrm{d}}$ Warm-up/cool-down exercises (e.g., stretching, flexibility).

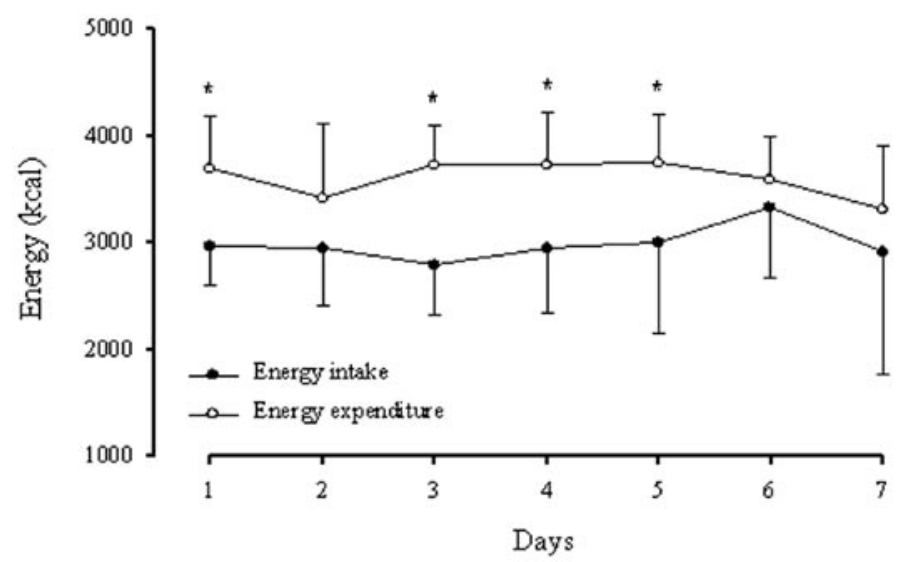

Figure 1- Energy intake and energy expenditure (mean \pm standard deviation) over the 7-d period. *Indicates a significant difference between estimated energy intake and expenditure.

and mainly in the form of water $(1113 \pm 269 \mathrm{~mL} ; 0.34 \pm 0.16 \mathrm{~mL} / \mathrm{kcal})$ and tea $(1243 \pm 348 \mathrm{~mL})$. No water was ingested before or during the early morning run, although only a modest amount of water was ingested after training and not by all athletes. Similarly, only a small amount of water was ingested after the afternoon run by a small number of the athletes. No water was ingested during the run. 


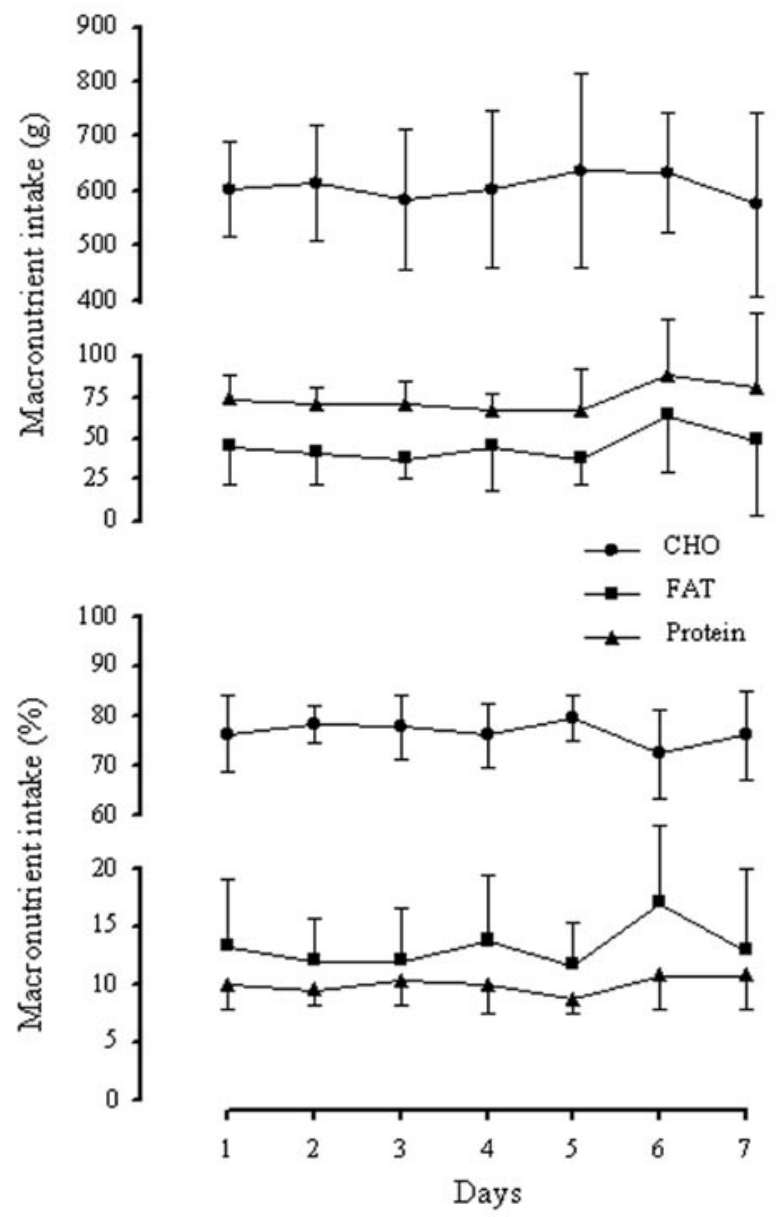

Figure 2 - Macronutrient intake ( $g$ and percent intake) (mean \pm standard deviation) over the 7-d period.

\section{Discussion}

The food and macronutrient content of elite Kenyan runners fulfilled most of the recommendations for endurance athletes for $\mathrm{CHO}$, fat, and protein intake, but not for energy (i.e., negative energy balance) and fluid intake (2). On the basis of this data, and from the two other dietary studies on Kenyan runners $(14,6)$, there is no evidence to support the notion that the Kenyan diet per se can explain the outstanding performances of Kenyan runners. If anything, there would appear to be room for considerable "improvements" in the nutritional practices of elite Kenyan runners, with particular reference to energy balance and fluid ingestion, assuming current recommendations would indeed be advantageous and not detrimental to the running performances of elite Kenyan runners. 
Table 3 Food Sources As a Percentage of Daily Intake of Each Macronutrient

\begin{tabular}{lrrrr}
\hline $\begin{array}{l}\text { Food } \\
\text { Sources }(\%)\end{array}$ & $\begin{array}{r}\text { Energy } \\
(\text { Kcal })\end{array}$ & $\begin{array}{c}\text { CHO } \\
(\mathrm{g})\end{array}$ & $\begin{array}{c}\text { Fat } \\
(\mathrm{g})\end{array}$ & $\begin{array}{c}\text { Protein } \\
(\mathrm{g})\end{array}$ \\
\hline Sugar & & 22 & 0 & 0 \\
Bread & 20 & 8 & 4 & 9 \\
Rice & 6 & 16 & 4 & 12 \\
Potatoes & 14 & 6 & 0 & 6 \\
Beans & 5 & 3 & 3 & 19 \\
Cabbage & 5 & 1 & 1 & 8 \\
Milk & 2 & 5 & 61 & 28 \\
Maize & 13 & 97 & 9 & 11 \\
Meat & 23 & 0 & 4 & 5 \\
Other & 1 & 12 & 14 & 11 \\
Animal & 11 & 5 & 65 & 33 \\
Vegetable & 14 & 95 & 35 & 67 \\
Mean & 86 & 607 & 46 & 75 \\
SD & 2987 & 57 & 14 & 12 \\
\hline
\end{tabular}

Note. SD, standard deviation. ${ }^{\text {SSugar }}$ consumed in tea and porridge. ${ }^{\mathrm{b}}$ Food sources that contribute less than $1 \%$.

The estimated daily EI ( $2987 \pm 293 \mathrm{kcal})$ of the elite Kenyan runners was lower than their daily EE $(3605 \pm 119 \mathrm{kcal})$ during the 7-d training period (Figure 1). This is also reflected by the low EI:EE ratio (i.e. EI/EE: $0.85 \pm 0.08$ ). The average daily EI of the runners was approximately $620 \mathrm{kcal}(17 \%)$ below the average estimated daily EE for the athletes. As there are $3500 \mathrm{kcal}$ in $454 \mathrm{~g}$ of body fat, it is estimated that this average daily negative energy intake (i.e. $620 \mathrm{kcal}$ ) would result in a loss of body mass of approximately $560 \mathrm{~g}$ in $1 \mathrm{wk}$, assuming all the loss was in the form of fat loss. As such, body mass (BM: $58.9 \pm 2.7 \mathrm{~kg}$ vs. $58.3 \pm 2.6$ $\mathrm{kg} ; P<0.001$ ) and percent body fat (percent BF: $10.4 \pm 2.4 \%$ vs. $9.6 \pm 2.5 \% ; P<$ 0.001 ) was significantly reduced over the $7 \mathrm{~d}$ by approximately this amount (Table 1). This finding is in agreement with current thinking that increasing EE does not lead to compensation of EI in the short term (i.e., 7 d) (24).

The remarkably low energy intake of male Kenyan runners first reported by Mukeshi and Thairu (14) - the validity of which was subsequently questioned by Christensen et al. (6) - might be accurate and an important advantageous feature of the Kenyan diet with regard to distance running performance. For example, elite Kenyan distance runners have been found to have a lower body mass index (BMI) and a more slender body shape compared to elite Caucasian distance runners (16). In a recent review of Kenyan dominance of distance running (12), it was argued that this lower BMI, body mass, and leg circumference was responsible for the superior running economy previously reported by Saltin et al. (16). It is interesting to note that Margaret Okayo, the female Kenyan runner who won the 2004 London Marathon, weighed only $39 \mathrm{~kg}$. Despite this, underreporting of habitual food intake 
by the athletes cannot be excluded in the present study and in the study by Mukeshi and Thairu (14). The fact that the athletes in the present study lost weight lends more credibility to the accuracy of food intake being lower than energy needs; it appears less likely that the athletes underreported food intake.

Endurance athletes are advised to strive to maintain fluid balance before, during, and after exercise to avoid a detriment in performance as a result of progressive dehydration (2). In the present study, given the greater need for fluids as the Kenyan runners lived and trained in a warm, high-altitude environment, their fluid intake was fairly modest and comprised of water $(1113 \pm 269 \mathrm{~mL} ; 0.34 \pm$ $0.16 \mathrm{~mL} / \mathrm{kcal})$ and tea $(1243 \pm 348 \mathrm{~mL})$. No fluids were ingested before or during training, although only a modest amount of water was ingested after training and not by all athletes. The previous two dietary studies in Kenyan runners $(14,6)$ made no particular reference to fluid intake, especially in relation to exercise training, and therefore it can be assumed that no specific strategies were adopted as in the present study. Although the drinking habits of these Kenyan runners is somewhat contrary to current dietary recommendations (2), it has recently been argued that some degree of dehydration could benefit marathon runners by increasing the pressure gradient across their capillary beds, increasing capillary flow rates, and decreasing intercapillary distances (9). It is common practice among elite Kenyan distance runners to consume considerably less fluid than is recommended. The overall significance of this has yet to be experimentally determined.

The composition of the Kenyan diet fulfilled most recommendations for endurance athletes for $\mathrm{CHO}$, fat, and protein intake (2). The diet was very high in carbohydrate $(76.5 \%, 607 \pm 57 \mathrm{~g}, 10.4 \mathrm{~g} / \mathrm{kg}$ BM per day) and correspondingly, very low in fat $(13.4 \%, 46 \pm 14 \mathrm{~g}$ ) (Figure 3, Table 3). This is in stark contrast to the macronutrient content of distance runners from industrialized countries. For example, the CHO intake of elite distance runners in the United States (10), the Netherlands (25), Australia (3), and Southern Africa (15) was 49\%, 50\%, 52\%, and $50 \%$, respectively. This difference in carbohydrate and fat intake between industrialized and nonindustrialized countries has been attributed to the greater availability of foods in industrialized countries (6). In addition to the favorable diet composition, the timing of the post-exercise meal was always within $60 \mathrm{~min}$ of exercise, therefore in line with current recommendations aimed at maximizing glycogen resynthesis rates after exercise (2). It is recommended that $\mathrm{CHO}$ intake begin immediately after exercise $(1.5 \mathrm{~g} \mathrm{CHO} / \mathrm{kg}$ at $2 \mathrm{~h}$ intervals $)$ resulting in higher glycogen levels at $6 \mathrm{~h}$ post-exercise than when ingestion is delayed for $2 \mathrm{~h}$.

The fat intake of the Kenyan runners should not be restricted further, as there would be no performance benefit in consuming a diet with much less than the current $13 \%$ of energy from fat; this might indeed be detrimental to their overall heath as fat provides energy, fat soluble vitamins, and essential fatty acids. For example, such a low-fat diet would almost certainly compromise intramuscular triacylglycerol concentration (7), with presently unknown consequences in endurance exercise performance (23). The protein intake of the Kenyan diet $(10.1 \% ; 1.3 \mathrm{~g} / \mathrm{kg} \mathrm{BM}$ per day, Figure 2) fell within the 1.2 to $1.4 \mathrm{~g} / \mathrm{kg} \mathrm{BM}$ per day recommendation for protein intake for endurance athletes and was primarily of vegetable origin (i.e., 67\%). As the Kenyan runners in the present study appeared to be in negative energy balance, maintaining the recommended protein intake would be vital for the health of the athletes. Negative energy balance can result in loss of muscle mass and increased 
risk of fatigue, injury, and illness (2). It is tempting, therefore, to ascribe the relatively fast "turnover" of elite Kenyan distance runners to this particular feature of the Kenyan diet (i.e., negative/borderline energy balance). Individual Kenyan runners tend to do well for a short time but "drop out" of the world running circuit or are unable to reproduce earlier running performances (personal communication with Brother Colm O'Connell, head coach of St. Patrick's High School, Iten, Kenya). For example, Kenyan Charles Kamathi, winner of the 10,000 m race at the 2001 World Championships in Edmonton, Canada, has not successfully performed on the world running circuit since defeating Haile Gebrselassie.

The subjects in the present study consumed a diet with a limited variety of foods, mainly of vegetable origin. This is in agreement with other published dietary studies of endurance athletes from low-income countries $(5,6)$. The staple foods - milk, sugar, bread, boiled rice, boiled potatoes, porridge, cabbage, kidney beans, and ugali-collectively accounting for $88 \%$ of total energy intake, with meat (i.e., mainly beef) comprising only about $1 \%$ of total energy intake. This high contribution from vegetable sources is very similar to the $90 \%$ previously reported $(5,6)$. The macronutrient distribution of the energy intake in the current study is also very similar to the two previous studies: CHO 71\% (5), 78\% (4), 77\% (current study); fat 15\%, 9\%, 13\%; protein 15\%, 13\%, 10\%, respectively. Despite the limited number of foods, there was no evidence of any malnourishment at the micronutrient level in these studies and the foods were generally considered to be of high nutritional quality.

\section{Conclusion}

The diet of elite Kenyan runners met recommendations for endurance athletes for $\mathrm{CHO}$, fat, and protein intake, but not for energy (i.e., negative energy balance) and fluid intake. It remains to be determined if dietary modifications in terms of energy balance and fluid intake will further enhance the performance of elite Kenyan runners.

\section{Acknowledgments}

The authors acknowledge the invaluable assistance of Athletics Kenya. The cooperation of all athletes, cooking staff, and the management at Global Sports Communication Camp, Kaptagat, Kenya, is greatly appreciated.

\section{References}

1. Ainsworth, B.E., W.L. Haskell, M.C. Whitt, M.L. Irwin, A.M. Swartz, S.J. Strath, et al. Compendium of physical activities: an update of activity codes and MET intensities. Med. Sci. Sports. Exerc. 32(9 Suppl):S498-S504, 2000.

2. American College of Sports Medicine, American Dietetic Association, and Dietitians of Canada; Joint Position Statement: Nutrition and Athletic Performance. Med. Sci. Sports. Exerc. 32(12):2130-2145, 2000.

3. Burke, L.M., R.A. Gollan, and R.S. Read. Dietary intakes and food use of groups of elite Australian male athletes. Int. J. Sport Nutr. 1(4):378-394, 1991.

4. Cable, A., D.C. Nieman, M. Austin, E. Hogen, A.C. Utter. Validity of leg-to-leg bioelectrical impedance measurement in males. J. Sports Med. Phys. Fitness. 41(3):411-414, 2001. 
5. Cerqueira, M.M., and W.E. Connor. The food and nutrient intakes of the Tarahumara Indians of Mexico. Am. J. Clin. Nutr. 32:905-915, 1979.

6. Christensen, L. D., V.G. Hall, and L. Habraeus. Food and macronutrient intake of male adolescent Kalenjin runners in Kenya. Br. J. Nutr. 88(6):711-717, 2002.

7. Coyle, E.F., A.E. Jeukendrup, M.C. Oseto, B.J. Hodgkinson, and T.W. Zderic. Lowfat diet alters intramuscular substrates and reduces lipolysis and fat oxidation during exercise. Am. J. Physiol. Endocrinol. Metab. 280(3): E391-E398, 2001.

8. Department of Health. Report on Health and Social Subjects. Dietary Reference Values for Food Energy and Nutrients for the United Kingdom. Report of the Panel on Dietary Reference Values of the Committee on Medical Aspects of Food Policy. London: HMSO, pp. xix, 1991.

9. Fiddian-Green, R.G. Published rapid responses to BMJ editorial: Timothy David Noakes: Overconsumption of fluids by athletes BMJ 327:113-114, 2003.

10. Grandjean, A.C. Macronutrient intake of US athletes compared with the general population and recommendations made for athletes. Am. J. Clin. Nutr. 49:1070-1076, 1989.

11. Hamilton, B. East African running dominance: what is behind it? Br. J. Sports Med. 34(5):391-394, 2000.

12. Larsen, H.B. Kenyan dominance in distance running. Comp. Biochem. Physiol. A. Mol. Integr. Physiol. 136(1):161-170, 2003.

13. Manners, J. Kenya's running tribe. The Sports Historian 17 (2):14-27, 1997.

14. Mukeshi, M., and K. Thairu. Nutrition and body build: a Kenyan review. World Rev. Nutr. Diet. 72:218-226, 1993.

15. Peters, E.M., and J.M. Goetzsche. Dietary practices of South African ultradistance runners. Int. J. Sports Nutr. 7:80-103, 1977.

16. Saltin, B., H. Larsen, N. Terrados, J. Bangsbo, T. Bak, C.K. Kim, J. Svedenhag, and C.J. Rolf. Aerobic exercise capacity at sea level and at altitude in Kenyan boys, junior and senior runners compared with Scandinavian runners. Scand. J. Med. Sci. Sports. 5(4):209-221, 1995.

17. Saltin, B. Exercise and the environment: focus on altitude. Res. Q. Exerc. Sport. 67(3 suppl): S1-S10, 1996.

18. Saunders, M.J., J.E. Blevins, and C.E. Broeder. Effects of hydration changes on bioelectrical impedance in endurance trained individuals. Med. Sci. Sports Exerc. 30(6): 885-892, 1998.

19. Schmidt, W., K. Heinicke, J. Rojas, J. Manuel Gomez, M. Serrato, M. Mora, B. Wolfarth, A. Schmid, and J. Keul. Blood volume and hemoglobin mass in endurance athletes from moderate altitude. Med. Sci. Sports Exerc. 34(12):1934-1940, 2002.

20. Schofield, W.N. Predicting basal metabolic rate, new standards and review of previous work. Hum. Nutr. Clin. Nutr. 39(1 suppl):5-41, 1985.

21. Scott, R.A., E. Georgiades, R.H. Wilson, W.H. Goodwin, B. Wolde, and Y.P. Pitsiladis. Demographic characteristics of elite Ethiopian endurance runners. Med. Sci. Sports Exerc. 35(10):1727-1732, 2003.

22. Sehmi, K. J. National food consumption tables and the planning of satistfactory diets in Kenya. Nairobi: The Kenya Government Press, 1993.

23. Spriet, L.L., and M.J. Gibala. Nutritional strategies to influence adaptations to training. J. Sports Sci. 22(1):127-141, 2004.

24. Stubbs, R.J., A. Sepp, D.A. Hughes, A.M. Johnstone, G.W. Horgan, N. King, and J. Blundell. The effect of graded levels of exercise on energy intake and balance in freeliving men, consuming their normal diet. Eur. J. Clin. Nutr. 56(2):129-140, 2002.

25. van Erp-Baart, A.M., W.H. Saris, R.A. Binkhorst, J.A. Vos, and J.W. Elvers. Nationwide survey on nutritional habits in elite athletes. Part I. Energy, carbohydrate, protein, and fat intake. Int. J. Sports Med. 10(1 suppl):S3-S10, 1989. 